\title{
High Grade Atrioventricular Block by ECG Finding
}

National Cancer Institute

\section{Source}

National Cancer Institute. High Grade Atrioventricular Block by ECG Finding. NCI

Thesaurus. Code C102642.

An electrocardiographic finding of intermittent failure of atrial electrical impulse conduction to the ventricles, characterized by two or more consecutive non-conducted $\mathrm{P}$ waves. (CDISC) 